\title{
The Gender and Education of Parents as Factors That Influence Their Views on Physical Education
}

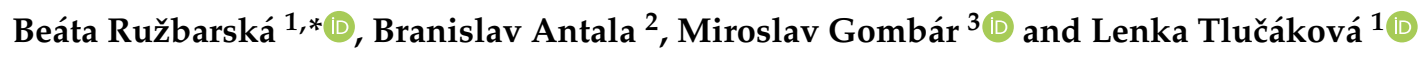 \\ 1 Faculty of Sports, University of Presov, 08001 Presov, Slovakia; lenka.tlucakova@unipo.sk \\ 2 Faculty of Physical Education and Sport, Comenius University Bratislava, 81469 Bratislava, Slovakia; \\ branislav.antala@uniba.sk \\ 3 Faculty of Management, University of Presov, 08001 Presov, Slovakia; miroslav.gombar@unipo.sk \\ * Correspondence: beata.ruzbarska@unipo.sk
}

check for updates

Citation: Ružbarská, B.; Antala, B.; Gombár, M.; Tlučáková, L. The Gender and Education of Parents as Factors That Influence Their Views on Physical Education. Sustainability 2021, 13, 13708. https://doi.org/ $10.3390 /$ su132413708

Academic Editor: Adela García-Aracil

Received: 9 November 2021

Accepted: 9 December 2021

Published: 12 December 2021

Publisher's Note: MDPI stays neutral with regard to jurisdictional claims in published maps and institutional affiliations.

Copyright: (c) 2021 by the authors. Licensee MDPI, Basel, Switzerland. This article is an open access article distributed under the terms and conditions of the Creative Commons Attribution (CC BY) license (https:/ / creativecommons.org/licenses/by/ $4.0 /)$.
Abstract: (1) The aim of this paper was to explore the views of primary and secondary school children's parents on physical education (PE) and to subsequently analyse the differences in their views. The gender of the parent and child was taken into consideration as well as the parents' levels of education. (2) The research sample consisted of 821 participants 668 of which were female $(81.4 \%)$ and 153 of which were male (18.6\%). The views of the children's parents were collected through a nonstandardized questionnaire. The questionnaire was divided into four areas (1-attitudes towards the physical education teaching process, 2-physical activity as part of lifestyle, 3-physical education during the COVID-19 pandemic, 4-social capital), with a total of 18 items in the questionnaire. The reliability of the questionnaire was analysed using Cronbach's coefficient reached 0.835 . Confirmatory factor analysis was also used to test the predicted factor structure. (3) In general, this research found that parents were more likely to express dissatisfaction if their child was only provided with $2 \mathrm{PE}$ classes per week and would accept an increase in this number. Those parents whose children do not participate in organized physical activities were shown to be unsatisfied with their children's physical fitness. A more significant limitation of children's physical activity (PA) was observed among parents with secondary education. Parents with secondary education also feel that their child partaking in PA when they have free time is not so important, whereas parents with a higher level of education feel that it is. (4) Parents expressed positive evaluations of PE and recognized the importance it has in their child's education. In the questionnaire, questions were related to physical fitness and PA specifically during the COVID-19 pandemic and this research observes the differences in opinions of parents depending on the level of education they attained and the gender of their child.

Keywords: physical activity; distance learning; gender differences; primary school; secondary school

\section{Introduction}

Physical education (PE) and living a healthy lifestyle have seen an increased disinterest and resentment in school children in recent years and this may be down to several things, including the deteriorating health status of the population around the world, the increasing obesity in children, adolescents and adults, and the earlier onset of civilisation diseases. These diseases are largely due to the increasing physical inactivity and sedentary lifestyles people are living [1]. Current research shows that $82.1 \%$ of adolescents live a sedentary lifestyle, with this rate being more prevalent among girls (87.8\%) [2]. Research shows that the self-perception of an adolescent's level of physical activity (PA) contrasts drastically with their actual level with statistics showing that $92.2 \%$ of boys and $81.7 \%$ of girls perceive themselves to be active, whereas research shows in fact over $80 \%$ of these adolescents live a sedentary lifestyle [3]. The environment in which children grow up in can support their active tendencies and these findings may provide scientific evidence for parents to strive to provide children with a home environment that incorporates PA. Such a change may be useful in addressing public health concerns about physical inactivity in adolescents [4]. 
PE should lead to the development of lifelong abilities and a relationship with physical and sporting activities in young children. Therefore, physical and sporting activities are modified in a way that young children enjoy participating in organised and unorganised physical activities throughout their life. An adolescent's PA is influenced by a complex of factors such as their family, school, and social and neighbourhood environments [5]. Several studies attribute the lack of adolescent PA to the school environment [6,7] and ignore the important role that the home environment plays in influencing an adolescents' active lifestyle. Apart from school, home is where adolescents spend most of their lives on a daily basis [8]. Attitudes towards sporting activities in adulthood are especially shaped in an individuals' youth and are something that are transmitted through a family's culture. The influence of the family environment on positive attitudes towards PA should not be overlooked [9], this is because the characteristics of the home environment, such as available sporting equipment, cause a greater variability in an adolescents' participation in PA compared to PA in the school environment [10]. We consider the influence of the family and environment to be important regarding a child's sedentary and active behaviours [11]. These characteristics of the home environment may be influenced by parental educational or income, consequently contributing to differences in children's sedentary behaviour, PA, and ultimately BMI [12]. Based on the above, it can be believed that children adopt the behavioural patterns and attitudes of their parents. Therefore, it is important to know the views of pupils' parents on PE to identify the variables that influence these attitudes.

Parents should be encouraged by both medical physicians and health professionals to increase their children's PA and reduce sedentary activities such as watching television or spending too much time on their phones, as these types of behaviours target obesity [13]. It is still under investigation as to what types of PA encourage a reduction in sedentary behaviour in children and how a parent's attitude, ethnicity, or other demographic variables may play a role. Identifying and understanding these mechanisms can make a significant contribution to the field of obesity prevention by designing effective interventions to combat it [14].

Parental support may also be a key factor in optimizing child's engagement in extracurricular PA [15]. There are many types of approaches for individuals to support and encourage PA and these vary based on a person's socioeconomic status (SES). Parents of children with a medium or high SES mainly provide them with logistical and financial support as well as participation opportunities. In contrast, support from parents with a low SES is mainly limited to verbal encouragement. Participation in joint family activities was equally more frequently reported in families with a higher SES compared with families with a low SES. All groups, regardless of their SES, claimed that the limiting factor for participation in family activities was mainly time. For families with a low SES, financial hardship is a particular barrier. It has also been shown that children from a background of medium to high SES are more likely to participate in organised physical activities in the form of sports club activities, whereas in contrast, children from a family with a low SES are more likely to participate in unstructured activities or 'free play' with their friends [16]. However, similar previous research conducted on the extent to which a family's SES influences their support for physical activities does not always support this statement. Instead, previous research has found that support for PA did not differ depending on SES [17].

Previous literature reports that the influence parents have on their children's level of PA as highly important [18,19]. Attitudes, behaviours, and the logistical support that parents provide to their children [20] is classified as significant and it strongly correlates to a child's PA participation levels. It is also worth noting that parents who overestimate their children's current PA levels may not provide the necessary support network needed to increase the child's level of PA [21,22]. Understanding parents' attitudes towards physical education and physical activity in general is helpful in setting the right forms of interventions and policies to promote active lifestyles among pupils. Should parents display a lax attitude towards physical education as a means of promoting physical activity in their children, the importance of physical education in the pupils' daily routine becomes 
all the more important. Uncovering the factors that may influence parents' attitudes towards PE lessons can help to target physical activity promotion policies at specific target groups where this support is needed.

The aim of this paper was to describe parents' attitudes towards PE and to identify the variables influencing the differences in parents' attitudes in terms of the parent's gender, the child's gender, and the parent's level of education.

\section{Materials and Methods}

The analysis of this research is divided into two parts. The first part relates directly to the characteristics of the participants. These items being Q1. Gender, Q2. Age and Q3. Education of the parents. The study consisted of $\mathrm{N}=821$ participants, $668(81.4 \%)$ of which were female and 153 (18.6\%) of which were male. In terms of education, 375 (45.7\%) of the participants had a secondary education and 446 respondents $(54.3 \%)$ had a university education. A more detailed analysis of the research sample in terms of gender (Q1), age (Q2) and education (Q3) is presented in Table 1 below. In terms of the child's gender, data collection shows that there were $381(46.4 \%)$ girls and $440(53.6 \%)$ boys.

Table 1. A Basic description of the research participants in terms of gender, age, and education.

\begin{tabular}{|c|c|c|c|c|c|c|c|c|c|c|c|c|}
\hline \multirow[b]{2}{*}{$N=821$} & \multicolumn{12}{|c|}{ Summary Table for All Multiple Response Items } \\
\hline & Q3 & Q1 & $\begin{array}{l}\text { Q2 } \\
25-30\end{array}$ & $\begin{array}{l}\text { Q2 } \\
31-35\end{array}$ & $\begin{array}{l}\text { Q2 } \\
36-40\end{array}$ & $\begin{array}{l}\text { Q2 } \\
41-45\end{array}$ & $\begin{array}{l}\text { Q2 } \\
46-50\end{array}$ & $\begin{array}{l}\text { Q2 } \\
51-55\end{array}$ & $\begin{array}{l}\text { Q2 } \\
56-60\end{array}$ & $\begin{array}{l}\text { Q2 } \\
61-65\end{array}$ & $\begin{array}{l}\text { Q2 } \\
65 \text { and More }\end{array}$ & $\begin{array}{l}\text { Row } \\
\text { Totals }\end{array}$ \\
\hline Count & secondary education & female & 2 & 26 & 94 & 120 & 50 & 9 & 3 & 1 & 0 & 305 \\
\hline Column Percent & & & $50.00 \%$ & $96.30 \%$ & $90.38 \%$ & $80.54 \%$ & $71.43 \%$ & $64.29 \%$ & $60.00 \%$ & $50.00 \%$ & & \\
\hline Row Percent & & & $0.66 \%$ & $8.52 \%$ & $30.82 \%$ & $39.34 \%$ & $16.39 \%$ & $2.95 \%$ & $0.98 \%$ & $0.33 \%$ & $0.00 \%$ & \\
\hline Table Percent & & & $0.53 \%$ & $6.93 \%$ & $25.07 \%$ & $32.00 \%$ & $13.33 \%$ & $2.40 \%$ & $0.80 \%$ & $0.27 \%$ & $0.00 \%$ & $81.33 \%$ \\
\hline Count & secondary education & male & 2 & 1 & 10 & 29 & 20 & 5 & 2 & 1 & 0 & 70 \\
\hline Column Percent & & & $50.00 \%$ & $3.70 \%$ & $9.62 \%$ & $19.46 \%$ & $28.57 \%$ & $35.71 \%$ & $40.00 \%$ & $50.00 \%$ & & \\
\hline Row Percent & & & $2.86 \%$ & $1.43 \%$ & $14.29 \%$ & $41.43 \%$ & $28.57 \%$ & $7.14 \%$ & $2.86 \%$ & $1.43 \%$ & $0.00 \%$ & \\
\hline Table Percent & & & $0.53 \%$ & $0.27 \%$ & $2.67 \%$ & $7.73 \%$ & $5.33 \%$ & $1.33 \%$ & $0.53 \%$ & $0.27 \%$ & $0.00 \%$ & $18.67 \%$ \\
\hline Count & & Total & 4 & 27 & 104 & 149 & 70 & 14 & 5 & 2 & 0 & 375 \\
\hline Table Percent & & & $1.07 \%$ & $7.20 \%$ & $27.73 \%$ & $39.73 \%$ & $18.67 \%$ & $3.73 \%$ & $1.33 \%$ & $0.53 \%$ & $0.00 \%$ & $100.00 \%$ \\
\hline Count & higher education & female & 2 & 11 & 72 & 177 & 78 & 22 & 1 & 0 & 0 & 363 \\
\hline Column Percent & & & $100.00 \%$ & $68.75 \%$ & $86.75 \%$ & $84.69 \%$ & $77.23 \%$ & $75.86 \%$ & $25.00 \%$ & $0.00 \%$ & $0.00 \%$ & \\
\hline Row Percent & & & $0.55 \%$ & $3.03 \%$ & $19.83 \%$ & $48.76 \%$ & $21.49 \%$ & $6.06 \%$ & $0.28 \%$ & $0.00 \%$ & $0.00 \%$ & \\
\hline Table Percent & & & $0.45 \%$ & $2.47 \%$ & $16.14 \%$ & $39.69 \%$ & $17.49 \%$ & $4.93 \%$ & $0.22 \%$ & $0.00 \%$ & $0.00 \%$ & $81.39 \%$ \\
\hline Count & higher education & male & 0 & 5 & 11 & 32 & 23 & 7 & 3 & 1 & 1 & 83 \\
\hline Column Percent & & & $0.00 \%$ & $31.25 \%$ & $13.25 \%$ & $15.31 \%$ & $22.77 \%$ & $24.14 \%$ & $75.00 \%$ & $100.00 \%$ & $100.00 \%$ & \\
\hline Row Percent & & & $0.00 \%$ & $6.02 \%$ & $13.25 \%$ & $38.55 \%$ & $27.71 \%$ & $8.43 \%$ & $3.61 \%$ & $1.20 \%$ & $1.20 \%$ & \\
\hline Table Percent & & & $0.00 \%$ & $1.12 \%$ & $2.47 \%$ & $7.17 \%$ & $5.16 \%$ & $1.57 \%$ & $0.67 \%$ & $0.22 \%$ & $0.22 \%$ & $18.61 \%$ \\
\hline Count & & Total & 2 & 16 & 83 & 209 & 101 & 29 & 4 & 1 & 1 & 446 \\
\hline Table Percent & & & $0.45 \%$ & $3.59 \%$ & $18.61 \%$ & $46.86 \%$ & $22.65 \%$ & $6.50 \%$ & $0.90 \%$ & $0.22 \%$ & $0.22 \%$ & $100.00 \%$ \\
\hline
\end{tabular}

To collect the data, a questionnaire called The Importance and Status of PE in Schools From the Perspective of Parents was used, which was designed to capture the issues present in parental opinions on PE during the pandemic. It was a non-standardized questionnaire which was created by the authors of the article (Ružbarská, Antala) for the needs of a research project aimed at mapping the quality and potential of physical education in health promotion from the perspective of pupils, teachers, and parents. This diagnostic tool was used for the first time, and in its creation the authors based it on the current social situation which was marked by the COVID-19 pandemic in a significant way. The questionnaire was converted into electronic form in Google Docs for ease of the participant. Data collection was conducted between January and March 2021. Primary and secondary schools in Slovakia were approached and informed about the purpose of the research. The contacted schools sent an online questionnaire to the e-mail addresses of the pupils parents on the basis of their own decision. This scientific research was approved by the Ethics Commission.

The anonymous questionnaire was composed of closed questions with a 5-point Likert scale (choices were: strongly agree, agree, don't know, disagree, strongly disagree). The reliability of the questionnaire was analysed using Cronbach's coefficient and the results 
showed the value of 0.835 , validating the reliability of the research and the tool used. A separate part of the questionnaire was the anamnesis data and the other questions were divided into 4 parts: Area 1 concerned the attitudes of the parents towards the teaching of PE, Area 2 looked to understand PA as part of a pupil lifestyle, Area 3 focused on the views of the parents regarding the interruption of PE during the pandemic lockdowns and subsequently the change in PE during this period, and Area 4 looked at social capital. The reliability measure found in the four different parts of the questionnaire equally confirms the reliability of the results found (Area 1-0.889; Area 2-0.756; Area 3-0.759; Area $4-0.836)$.

The questionnaire that the participants completed is shown in Table 2 below.

Table 2. The questionnaire completed by participants which looks at the importance and status of PE in schools from a parent's point of view.

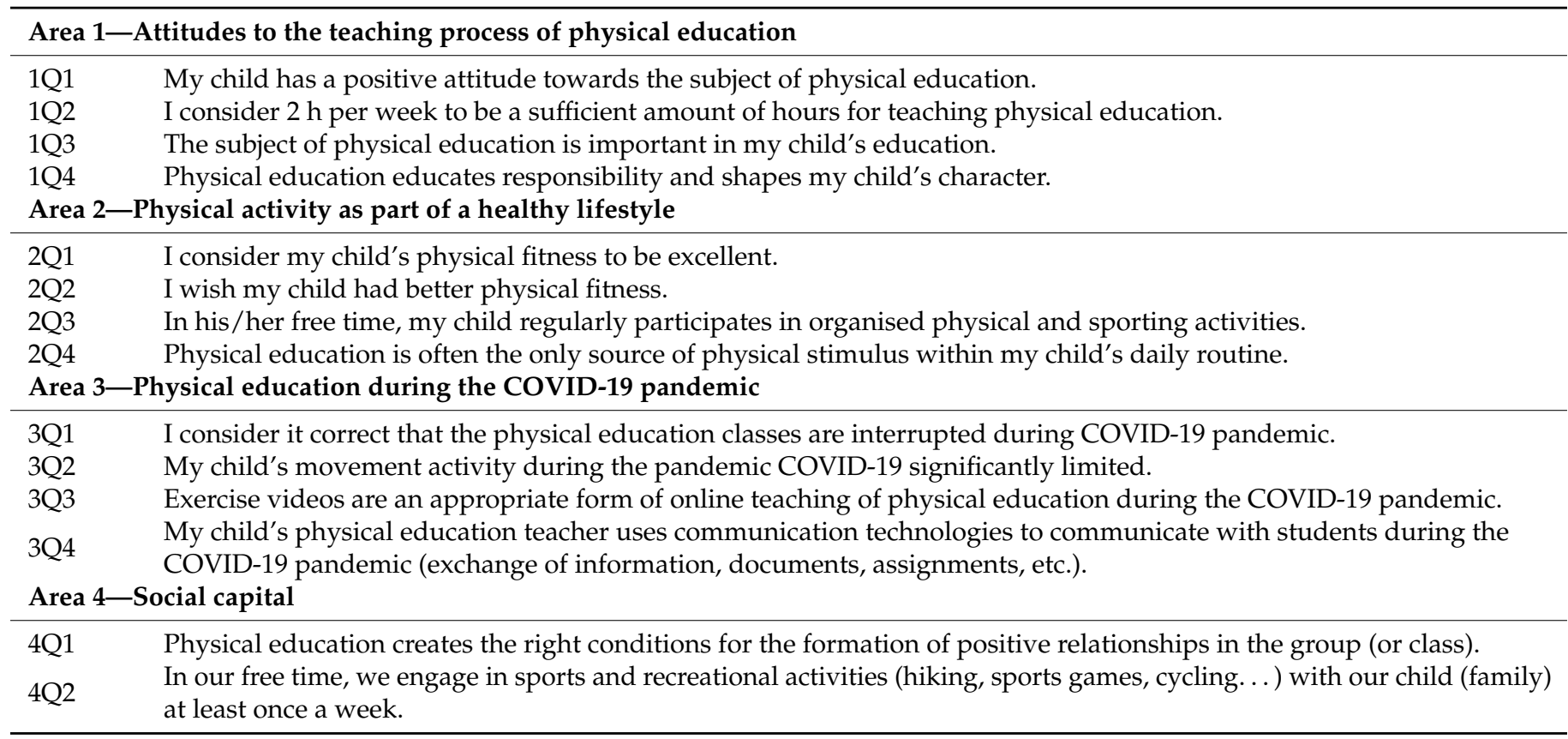

Data processing was performed using IBM SPSS Amos 26, IBM SPSS Statistics 26 and Statistica 13.5 and confirmatory factor analysis was used to verify the predicted factor structure. In this study, we chose the maximum likelihood method. In selecting the CFA method, we were guided by the research results $[23,24]$ that accept the application of classical cut-off estimators' method ML, even in the case of ordinal variables if the research has at least 5 response categories. The distribution of responses to all items of the research followed a normal distribution. The normality of the respondents' answers was tested through the Shapiro-Wilk test and showed a $\alpha=0.05$ level of significance.

We used the following procedures and indices to test the suitability of the validated model: chi-square statistics and the following overall fit indices with optimal values: $(\chi 2 / \mathrm{df}<2$, RMSEA $<0.08$, comparative index TLI $>0.90$, CFI $>0.90$, SRMR $<0.08)$ and sub-indices (statistical significance of model parameters).

From Table 3 shown above, it is clear that the recommended indices evaluating the factor model (Figure 1) are acceptable and justify the fact that the developed hypothetical model presents a good level of fitness with the real data and is applicable in this form. Other indicators were $\chi 2=52.770, \mathrm{df}=38, p=0.056$. 
Table 3. CFA Fit Indices for the overall model.

\begin{tabular}{|c|c|c|c|c|}
\hline Fit Indices Used & Perfect Fit Indices & Acceptable Fit Indices & CFA Results & References \\
\hline$x^{2 / d f}$ & $0 \leq \chi^{2} / \mathrm{df} \leq 2$ & $2 \leq \chi^{2} / \mathrm{df} \leq 3$ & 1.388 & [25] \\
\hline GFI & $0.95 \leq \mathrm{GFI} \leq 1.00$ & $0.90 \leq \mathrm{GFI} \leq 0.95$ & 0.991 & \multirow{2}{*}[26,27]{} \\
\hline AGFI & $0.90 \leq \mathrm{AGFI} \leq 1.00$ & $0.85 \leq \mathrm{AGFI} \leq 0.90$ & 0.976 & \\
\hline CFI & $0.95 \leq \mathrm{CFI} \leq 1.00$ & $0.90 \leq \mathrm{CFI} \leq 0.95$ & 0.993 & \multirow{3}{*}[28-30]{} \\
\hline NFI & $0.95 \leq \mathrm{NFI} \leq 1.00$ & $0.90 \leq \mathrm{NFI} \leq 0.95$ & 0.977 & \\
\hline TLI & $0.97 \leq \mathrm{TLI} \leq 1.00$ & $0.95 \leq \mathrm{TLI} \leq 0.97$ & 0.984 & \\
\hline RMSEA & $0.00 \leq \mathrm{RMSEA} \leq 0.05$ & $0.05 \leq \mathrm{RMSEA} \leq 0.08$ & 0.022 & \multirow{2}{*}[27,31-33]{} \\
\hline SRMR & $0.00 \leq \mathrm{SRMR} \leq 0.05$ & $0.05 \leq \mathrm{SRMR} \leq 0.10$ & 0.025 & \\
\hline
\end{tabular}

x2—chi-square, df-degrees of freedom, GFI—goodness of fit index, AGFI—adjusted goodness of fit index, CFI—comparative fit index, NFI-The Bentler-Bonett normed fit index, TLI-Tucker-Lewis coefficient, RMSEA-root mean square error of approximation, SRMR—standardized root mean square residual.

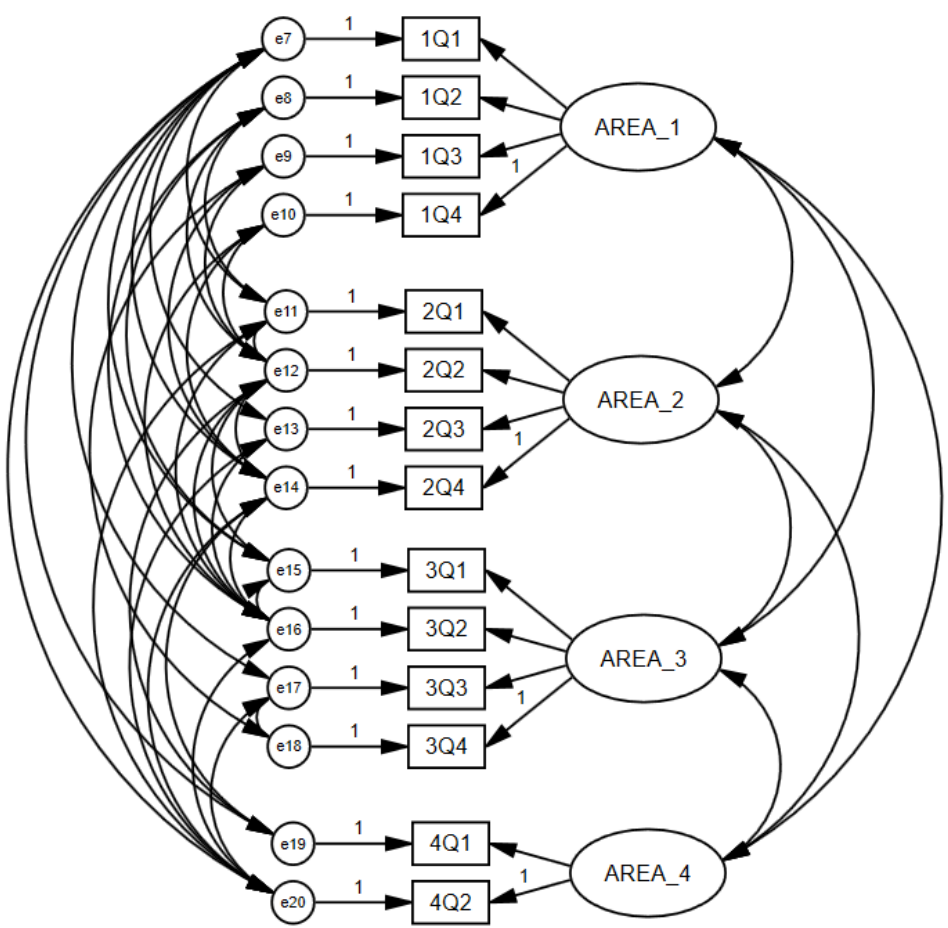

Figure 1. 4-factor model of parents' attitudes towards PE.

Confirmatory factor analysis on a sample of $\mathrm{N}=821$ respondents was used to test the theoretical factor structure which consisted of 4 defined areas. Based on it, we drew inferences of respondents' attitudes toward the defined areas and, at the same time, differences in respondents' attitudes toward the 4 defined areas depending on respondents' gender, respondents' education, and respondents' child's gender. The theoretical model (Figure 1) was verified in terms of applicability by evaluation criteria (Table 3) and likewise the differences of attitudes depending on the abovementioned indicators were observed (Table 4). 
Table 4. CFA Fit Indices for partial models.

\begin{tabular}{ccccccc}
\hline \multirow{2}{*}{ Fit Indicies Used } & \multicolumn{2}{c}{ Gender } & \multicolumn{2}{c}{ Education } & \multicolumn{2}{c}{ Child } \\
\cline { 2 - 7 } & $\mathbf{M}$ & $\mathbf{F}$ & $\mathbf{S}$ & $\mathbf{H}$ & $\mathbf{B}$ & $\mathbf{G}$ \\
\hline$\chi 2 / \mathrm{df}$ & 0.755 & 1.088 & 1.223 & 1.389 & 0.768 & 1.031 \\
GFI & 0.978 & 0.992 & 0.981 & 0.991 & 0.991 & 0.987 \\
AGFI & 0.928 & 0.976 & 0.957 & 0.976 & 0.974 & 0.961 \\
CFI & 0.999 & 0.998 & 0.994 & 0.993 & 1.000 & 0.999 \\
NFI & 0.962 & 0.979 & 0.954 & 0.977 & 0.978 & 0.970 \\
TLI & 0.997 & 0.995 & 0.989 & 0.984 & 0.988 & 0.997 \\
RMSEA & 0.000 & 0.012 & 0.018 & 0.022 & 0.000 & 0.009 \\
SRMR & 0.039 & 0.023 & 0.032 & 0.025 & 0.023 & 0.032 \\
$p(\chi 2)$ & 0.838 & 0.328 & 0.261 & 0.056 & 0.840 & 0.418 \\
\hline
\end{tabular}

X2-chi-square, $\mathrm{df}$ - degrees of freedom, GFI-goodness of fit index, AGFI-adjusted goodness of fit index, CFI-comparative fit index, NFI-The Bentler-Bonett normed fit index, TLI-Tucker-Lewis coefficient, RMSEA - root mean square error of approximation, SRMR - standardized root mean square residual, $p$-probability level, M-man, F-woman, S-secondary, H-high, B-boy, G-girl.

\section{Results}

The analysis of the 4-factor model which looks at parents' attitudes towards PE for this research set $(\mathrm{N}=821)$ is shown in Table 5. For Area 1, parents' attitudes towards PE were found to be significant $(\alpha=0.05)$. The correlations between the exogenous variables and the questions on the questionnaire, were positive except for item 1Q2 (Q8). This shows that it is evident that parents do not consider $2 \mathrm{~h}$ of PE per week to be sufficient. For Area 2, PA as part of a healthy lifestyle, all the associations between endogenous and exogenous variables were equally significant. The research found a negative association for questionnaire item 2Q1 (Q11) and 2Q3 (Q13). Meaning that parents are not satisfied with their child's physical fitness (2Q1) and that their children do not regularly participate in organized sports activities in their free time (2Q3). For Area 3, the section about PE during the pandemic, two statistically insignificant associations were observed, namely for items 3Q4 (the PE teacher used technology to communicate with students during the pandemic) and item 3Q2 (the child's PA was significantly limited during the pandemic). A negative association with item 3Q1 was also observed, showing that parents do not consider it right to interrupt and hinder a child's PE due to the pandemic. In Area 4, about social capital, both items were found to be significant. From the results, parents give more weight to item $4 \mathrm{Q} 1$ and thus agree with the view that PE creates appropriate conditions for the formation of positive relationships in the classroom.

Table 5. Regression weights and standard errors of parents' attitudes towards PE.

\begin{tabular}{cccccccc}
\hline & Relationship & & Estimate & Std. Estimate & Std. Error & t-Statistic & $p$-Value \\
\hline Q10 (1Q4) & $<-$ & AREA_1 & 1.000 & 0.739 & 0.098 & 14.652 & $0.000^{*}$ \\
Q9 (1Q3) & $<-$ & AREA_1 & 0.833 & 0.728 & 0.061 & 13.683 & $0.000^{*}$ \\
Q1 (1Q2) & $<-$ & AREA_1 & -0.545 & -0.262 & 0.085 & -6.428 & $0.000^{*}$ \\
Q7 (1Q1) & $<-$ & AREA_1 & 0.595 & 0.450 & 0.056 & 10.64 & $0.000 *$ \\
\hline Q14 (2Q4) & $<-$ & AREA_2 & 1.000 & 0.437 & 0.077 & 9.882 & $0.000 *$ \\
Q13 (2Q3) & $<-$ & AREA_2 & -1.776 & -0.827 & 0.170 & -10.461 & $0.000 *$ \\
Q12 (2Q2) & $<-$ & AREA_2 & 0.245 & 0.161 & 0.058 & 4.229 & $0.000 *$ \\
Q11 (2Q1) & $<-$ & AREA_2 & -1.405 & -0.731 & 0.130 & -10.802 & $0.000 *$ \\
\hline Q18 (3Q4) & $<-$ & AREA_3 & 1.000 & 0.060 & 0.046 & 0.742 & 0.127 \\
Q17 (3Q3) & $<-$ & AREA_3 & 0.988 & 0.069 & 0.338 & 2.924 & $0.003 *$ \\
Q16 (3Q2) & $<-$ & AREA_3 & 0.708 & 0.043 & 0.371 & 1.910 & 0.056 \\
Q15 (3Q1) & $<-$ & AREA_3 & -2.695 & -0.145 & 0.851 & -3.168 & $0.002 *$ \\
\hline Q20 (4Q2) & $<-$ & AREA_4 & 1.000 & 0.307 & 0.093 & 2.416 & 0.190 \\
Q19 (4Q1) & $<-$ & AREA_4 & 1.515 & 0.636 & 0.245 & $0.008 *$ \\
\hline
\end{tabular}

* — significant at the level of significance $\alpha=0.05$, Estimate—estimate, Std. Estimate—standardized regression weight, Std. error-standard error, $\mathrm{t}$ - -statistic, $p$ - probability level. 
For further analysis of the interrelationships and comparisons between the basic characteristics of the participants, a basic model for the whole population was applied (Figure 1), however an adjustment of the individual models using modification indices was also applied. The basic indicators of the individual models that define the accuracy and applicability of the individual models are shown in Table 4 and the permissible values of the individual indices are shown in Table 3.

\subsection{Parents' Views on PE in Terms of Their Educational Backgrounds}

When assessing the basic differences of parents' opinions towards PE and PA in relation to their education, we see that parents with secondary education consider all correlations between the answered questions to be significant. In contrast, parents with a university education do not consider the relationship of item 3Q2 (Q16: my child's physical activity was significantly limited during the COVID-19 pandemic) and Part $3(p=0.056)$ not to be significant. Another significant difference was observed through the relationship of item 2Q2 (Q12 hence I wish my child had better physical fitness) and Area 2. While parents with a high school education are on a significantly negative response scale $(-0.769)$, contrastingly, parents with a university education are on a positive response scale (0.161). Another difference is observed in the strength of these relationships. While parents with a high school education attach relatively high importance (0.602) to the relationship between questionnaire item 1Q1 (Q7) and Area 1, parents with a university education perceive their child's positive relationship towards PE to be weaker (0.450) (Table 6).

Table 6. Regression weights and standard errors of parents' attitudes towards PE.

\begin{tabular}{|c|c|c|c|c|c|c|c|c|c|c|}
\hline \multirow{2}{*}{\multicolumn{3}{|c|}{ Relationship }} & \multicolumn{4}{|c|}{ Secondary Education } & \multicolumn{4}{|c|}{ University Education } \\
\hline & & & \multirow{2}{*}{$\begin{array}{c}\text { Std. Estim. } \\
0.762\end{array}$} & \multirow{2}{*}{$\begin{array}{c}\text { Std.e. } \\
0.106\end{array}$} & \multirow{2}{*}{$\frac{\mathbf{t}}{11.249}$} & \multirow{2}{*}{$\frac{p}{0.000 *}$} & \multirow{2}{*}{$\begin{array}{c}\text { Std. Estim. } \\
0.739\end{array}$} & \multirow{2}{*}{$\begin{array}{c}\text { Std.e. } \\
0.065\end{array}$} & \multirow{2}{*}{$\frac{\mathbf{t}}{14.352}$} & \multirow{2}{*}{$\frac{p}{0.000 *}$} \\
\hline Q10 (1Q4) & $<-$ & AREA_1 & & & & & & & & \\
\hline Q9 (1Q3) & $<-$ & AREA_1 & 0.744 & 0.077 & 10.963 & 0.000 * & 0.728 & 0.061 & 13.683 & 0.000 * \\
\hline Q8 (1Q2) & $<-$ & AREA_1 & -0.230 & 0.110 & -4.051 & 0.000 * & -0.262 & 0.085 & -6.428 & 0.000 * \\
\hline Q7 (1Q1) & $<-$ & AREA_1 & 0.602 & 0.083 & 9.244 & 0.000 * & 0.450 & 0.056 & 10.640 & 0.000 * \\
\hline Q14 (2Q4) & $<-$ & AREA_2 & 0.347 & 0.062 & 5.663 & 0.000 * & 0.437 & 0.084 & 5.202 & $0.000 *$ \\
\hline Q13 (2Q3) & $<-$ & AREA_2 & -0.798 & 0.387 & -5.468 & 0.000 * & -0.827 & 0.170 & -10.461 & $0.000 *$ \\
\hline Q12 (2Q2) & $<-$ & AREA_2 & -0.769 & 0.432 & -3.366 & 0.000 * & 0.161 & 0.058 & 4.229 & $0.000 *$ \\
\hline Q11 (2Q1) & $<-$ & AREA_2 & -0.704 & 0.298 & -5.614 & 0.000 * & -0.731 & 0.130 & -10.802 & 0.000 * \\
\hline Q18 (3Q4) & $<-$ & AREA_3 & 0.061 & 0.194 & 3.559 & 0.000 * & 0.060 & 0.011 & 5.455 & 0.000 * \\
\hline Q17 (3Q3) & $<-$ & AREA_3 & 0.051 & 0.234 & 3.054 & 0.002 * & 0.069 & 0.338 & 2.924 & 0.003 * \\
\hline Q16 (3Q2) & $<-$ & AREA_3 & 0.036 & 0.306 & 2.017 & 0.044 * & 0.043 & 0.371 & 1.910 & 0.056 \\
\hline Q15 (3Q1) & $<-$ & AREA_3 & -0.101 & 0.558 & -3.528 & 0.000 * & -0.145 & 0.851 & -3.168 & 0.002 * \\
\hline Q20 (4Q2) & $<-$ & AREA_4 & 0.322 & 0.163 & 4.897 & 0.000 * & 0.307 & 0.097 & 3.165 & 0.000 * \\
\hline Q19 (4Q1) & $<-$ & AREA_4 & 0.549 & 0.223 & 5.384 & 0.000 * & 0.636 & 0.245 & 6.190 & 0.000 * \\
\hline
\end{tabular}

*-significant at the level of significance $\alpha=0.05$, Std. Estim.—standardized regression weight, Std.e.—standard error, $\mathrm{t}$ - $\mathrm{t}$-statistic, $p$-probability level.

\subsection{Parents' Views on PE from the Perspective of Both Their and Their Child's Gender}

For a more detailed analysis of parents' attitudes towards PE and to find out their mutual differences, the parent's gender and their child's gender was analysed in relation to their answers. The basic identification indicators of the fit of the partial models, which are identical to the model in Figure 1, are presented in Table 7 below. 
Table 7. CFA fit indices for partial combination models.

\begin{tabular}{ccccc}
\hline \multirow{2}{*}{ Fit Indicies Used } & \multicolumn{4}{c}{ Gender of Parents $\rightarrow$ Gender of Child } \\
\cline { 2 - 5 } & $\mathbf{M} \rightarrow \mathbf{B}$ & $\mathbf{M} \rightarrow \mathbf{G}$ & $\mathbf{F} \rightarrow \mathbf{B}$ & $\mathbf{F} \rightarrow \mathbf{G}$ \\
\hline$\chi 2 / \mathrm{df}$ & 1.269 & 1.173 & 1.261 & 1.333 \\
GFI & 0.943 & 0.907 & 0.981 & 0.979 \\
AGFI & 0.858 & 0.853 & 0.946 & 0.942 \\
CFI & 0.977 & 0.955 & 0.988 & 0.987 \\
NFI & 0.910 & 0.902 & 0.947 & 0.951 \\
TLI & 0.951 & 0.950 & 0.971 & 0.968 \\
RMSEA & 0.053 & 0.056 & 0.028 & 0.032 \\
SRMR & 0.065 & 0.071 & 0.038 & 0.041 \\
$p(\chi 2)$ & 0.133 & 0.215 & 0.130 & 0.082 \\
\hline
\end{tabular}

$\chi_{2}$-chi-square, df-degrees of freedom, GFI-goodness of fit index, AGFI-adjusted goodness of fit index, CFI-comparative fit index, NFI-The Bentler-Bonett normed fit index, TLI-Tucker-Lewis coefficient, RMSEA—root mean square error of approximation, SRMR — standardized root mean square residual, $p$-probability level, M-man, F-woman, B-boy, G-girl.

Figure 2 shows that fathers with a daughter consider it unimportant that their child has $2 \mathrm{~h}$ of PE per week as part of her schooling (1Q2, $p=0.124)$. Another difference from other combinations of parent's and child's genders was observed in the group of fathers with a daughter on the issue of better physical fitness of the child $(2 \mathrm{Q} 2)$, where they equally do not consider it important $(p=0.518)$. The same group of fathers with daughters equally do not consider 4Q1 $(p=0.081)$ and 4Q2 $(p=0.085)$ questionnaire items as essential unlike the other groups in comparison $(\alpha=0.05)$. Another interesting significant difference was found in the group of fathers who have a son. This group, unlike the other matched groups of participants, attaches importance to items 3Q1 $(p=0.010), 3 \mathrm{Q} 4(p=0.023)$ and 3Q4 $(p=0.025)$.

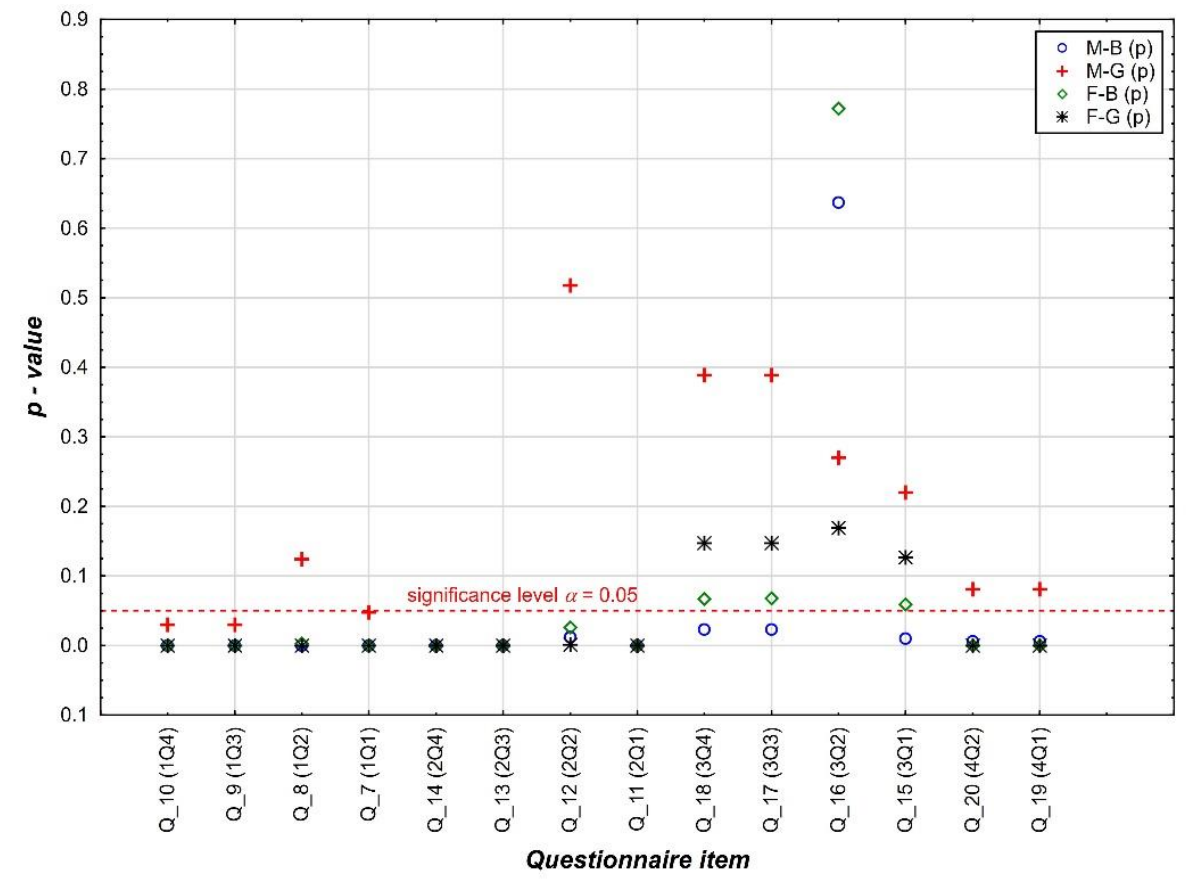

Figure 2. The statistical significance of the individual questions in terms of the combination of both the respondent's gender and their child's gender.

In terms of the degree of importance, the 2Q3 item for the matched groups showed the most significant differences. Here it is clear that fathers with daughters have a highly positive attitude towards their child's regular participation in organised physical and sporting activities in contrast to the other groups who disagree with this statement. Similarly, fathers 
with daughters consider their child's physical fitness to be excellent (2Q1), unlike the other groups in comparison. Fathers with a son take an agreeing position with the statement that $\mathrm{PE}$ is often the only source of physical activity within the child's daily routine, whereas in contrast, the other groups disagree with this statement. Fathers with sons also consider questionnaire items 3Q1, 3Q2, 3Q3 to be important, unlike the other comparison groups. From the responses of this group of parents, fathers with a son do not consider it correct that PE was affected due to the pandemic. On the contrary, this group are very positive about the fact that exercise videos are available to their children, which they consider to be an appropriate form of PE. They are also positive about the fact that their child's PE teacher uses technology to communicate with pupils during the pandemic and the interruption of regular schooling.

\section{Discussion}

An increasing number of countries throughout the world are trying to implement $3 \mathrm{~h}$ of compulsory PE per week. The 2003 Council of Europe called for the provision of one hour of PA per day, either in school or external to school [1]. The time allocations for the subjects taught were set by the curriculum frameworks of the National Curriculum. Under the Education Act, the time allocation is defined over the total number of hours of education, and it is up to the school to allocate the time to the individual year groups for specific subjects. Schools generally include two compulsory lessons of PE per year group, while schools have the possibility to extend this allocation in terms of optional lessons. The subjects of the optional lessons are usually assigned to the educational area or subject on which a particular school focuses [34]. Based on the results of the questionnaire, it can be concluded that parents are generally aware of the importance of PE and are in favour of increasing the number of lessons, as they expressed their dissatisfaction with just 2 lessons per week.

Research shows that people who overestimate their PA levels may ignore campaigns to promote increasing it as if the campaigns were only targeting inactive people [35]. The results of this study show that parents approached the assessment of their child's level of physical fitness in a critical way and did not consider it to be excellent. At the same time, they would also like their children's level of physical fitness to improve, as parents whose children do not regularly participate in organised physical activities are particularly dissatisfied with the level of their child's physical fitness. The critical attitude of the parents found in this research is not in line with previous research describing an overestimation of PA levels [21,36].

The current and ongoing pandemic has forced national governments to implement movement restriction measures of various levels to halt the spread of the disease. These restrictions affect the education sector, which has been required to transform its educational processes to online teaching [37]. Each level and type of school has its own forms of online teaching and the subjects that they teach vary. One of the subjects that receives insufficient attention in primary and secondary schools in Slovakia is PE. In addition to the measures that have significantly reduced the daily exercise and PA of the population [38], it is important to consider that exercise should not be eliminated from the daily routine of children and young people. Research indicates that quarantine during COVID-19 significantly disrupted lifestyle activities, including participation in physical and sporting activities [39]. The results of this research indicate general parental disapproval of the interruption of PE classes during this period, but they also indicate that parents acknowledge that their children's PA was limited due to the pandemic-related measures that were enforced. Thus, online education without PE classes and curfews are both significant risk factors for reduced PA and increased sedentary behaviour in young individuals.

Differences in terms of education

The higher SES of a parent may be associated with greater awareness of screen time recommendations for their children and the ability to implement the limit suggested by these recommendations. Social status may equally influence how well a person is able 
to adopt preventive health knowledge [40]. This research evaluated the differences in attitudes in terms of a parents' education level and observed a significant difference in children's ratings of physical fitness compared to their parents' educational level. Parents were asked if they wished their child's physical fitness was better and parents with a university education showed a significantly more positive attitude compared with parents with a secondary level of education. The latter expressed a negative attitude towards this statement, leading this research to determine that parents with a university education are more aware of the importance of PA and the associated sufficient level of physical fitness in terms of health promotion related to their child.

PA in young children is mostly informal and may not require a large financial outlay from parents [41]. However, as the amount of informal PA decreases with age and the associated costs of participation in sporting activities increase, research suggests that income differences are more influential on adolescents' [41] and adults' [42] PA. Comparison in parental responses in terms of educational level, focusing on assessments of PA during both school dropout and PE classes, suggests that children of parents with a high-school education had a significantly more limited level of PA participation. This result may again be related to the fact that parents with a university education tried to compensate adequately for this deficit because of their knowledge on the importance of regular PA. The characteristics of the home environment, such as the sports equipment and exercise tools available can also impact the frequency of an adolescents' PA [10]. The ability for an adolescent to be creative in partaking in home exercise may be something that is only realized through having parents with a university education.

Parents usually overestimate the amount of PA their children partake in [36]. It is important to educate parents and society in general about the recommended amount of PA that a child should do, as parents' lack of awareness could contribute to perpetuating the problem of inactivity in their child [21,22]. Based on the results of this research, support for PA and the awareness of a sufficient level of physical fitness is more evident in parents with a university education. However, in the questionnaire item concerning the child's attitude towards PE, the opposite difference between parents in terms of educational level was observed. Results show that parents of children with secondary education think that their child has a more positive attitude towards PE compared with the children of parents with a university education.

\section{Gender differences}

Previous studies point towards gender-biased views in children [43,44], and understanding the origins of gender differences may help to explain the reasoning as to why girls have lower levels of PA and more sedentary behaviour than boys [45]. This trend is shown through multiple previous studies on Slovak secondary school children, where on average girls spend more time per day sitting compared to boys. Adolescents spend more than $6 \mathrm{~h}$ a day sitting and of the total sitting time on weekdays, more than $2 \mathrm{~h}$ per day were spent watching television [46]. Further research examining the amount of PA in adolescents found that $28 \%$ of boys achieved the WHO's recommended amount of PA for adolescents, whereas only $19 \%$ of girls met these recommendations [47]. The difference between the sexes in the performance of PA of different intensities can be attributed to biological factors and the sociocultural environment [48]. Even though research shows a lower level of PA in girls, in this research study, gender differences in assessing the physical performance of children was explored. It has been shown that men with daughters consider their daughters' physical fitness to be excellent and do not attach importance to further increasing their level of physical fitness. Significantly positive attitudes were expressed by fathers with daughters towards participation in organized physical sporting activities, but this significant relationship was not confirmed when assessing the importance of PE classes. They do not consider the number of PE lessons their daughters partake in or their increase in PA to be important. Although parents generally acknowledge the importance of PE in forming group relationships, this trend was not confirmed in the group of fathers with daughters, and they do not consider PE to be an important form of forming group 
relationships. This group of fathers, compared with the other parental groups, also did not attach any importance to spending leisure time together with the family to partake in sports and physical activities. However, parents significantly influence their children's behaviour and if they have a positive attitude towards performing physical activities in this form, it can lead to an increase in PA and a decrease in sedentary behaviour in their children [49]. Adolescents in families where parents are willing to exercise with their children and encourage their children's participation in PA are likely to be more active than those who don't [50]. A more critical perspective is seen in the group of fathers with sons as they consider PE to be the only source of PA for their sons. This was also reflected in the evaluation of the interruption of PE during the pandemic. The fathers with sons did not consider it right that PE was interrupted, and they considered it equally important that the PE teacher communicated with pupils through ICT. Exercise videos were considered, especially by fathers with sons, as an appropriate form of replacement PE lessons. These results may suggest a more rigorous view of the implementation of physical activities within the context of parent-child gender matching. Conversely, a more generous approach to assessing PA appears to be taken when assessing the parent-child of the opposite sex, specifically in the conditions of the father-daughter aspect in this research. Some studies suggest that the role fathers play, in terms of influencing their children's movement habits, has a greater impact than those of mothers. The role of fathers is also more effective in promoting healthy lifestyles in sons as opposed to daughters $[19,51,52]$. This theory is supported by previous research confirming that role modelling of PA in same-sex parent-child dyads may have a more positive impact on adolescents' PA behaviours, compared with opposite-sex parent-child dyads. This may be explained by gender-role identity during adolescence [4]. However, another study contradicts the results of this research. The said study describes how both fathers' and mothers' reflections were more likely to include instances of overestimation in relation to sons and instances of underestimation in relation to daughters, suggesting that parents apply differential perceptual filters according to the child's gender when assessing the level of PA [21].

\section{Limitations}

The most significant limitation of our work is the questionnaire which has not undergone a process of standardization. At the same time, more objective data would have been provided by a larger research sample, where both sexes of parents would have been proportionally represented. We are aware that the number of children in the family may also be a factor significantly influencing parents' opinion on physical education. This factor was not surveyed by the questionnaire used. This fact may be of interest for further research.

Author Contributions: Conceptualization, B.R. and B.A.; methodology, B.R. and M.G.; software, M.G.; validation, M.G.; formal analysis, M.G. and B.R. investigation, B.R. and L.T.; resources, B.R.; data curation, B.R. and L.T.; writing-original draft preparation, B.R.; writing-review and editing, B.R.; visualization, B.R.; supervision, B.A.; project administration, B.A.; funding acquisition, B.A. All authors have read and agreed to the published version of the manuscript.

Funding: The study was supported by The Scientific Grant Agency of the Ministry of Education, Science, Research and Sport of the Slovak Republic (VEGA) with number 1/0523/19. It was titled "Physical and Sports Education and its Quality and Potential in Promoting Health from the Perspective of Pupils, Teachers and Parents".

Institutional Review Board Statement: This scientific research was approved by the Ethics Commission of the Faculty of Physical Education and Sport of Comenius University in Bratislava under number 9/2019.

Informed Consent Statement: Informed consent was obtained from all subjects involved in the study.

Data Availability Statement: Data are available based upon the request.

Conflicts of Interest: The authors declare no conflict of interest. 


\section{References}

1. Antala, B.; Olosová, G. International Aspects of School Physical Education and Its Management; Slovak Scientific Society for Physical Education and Sport: Bratislava, Slovakia, 2016; 184p.

2. Guthold, R.; Stevens, G.A.; Riley, L.M.; Bull, F.C. Global trends in insufficient physical activity among adolescents: A pooled analysis of 298 population-based surveys with 1.6 million participants. Lancet Child Adolesc. Health 2020, 4, 23-35. [CrossRef]

3. Lago-Ballesteros, J.; García-Pascual, M.; González-Valeiro, M.; Fernández-Villarino, M. Gender Influences on Physical Activity Awareness of Adolescents and Their Parents. Int. J. Environ. Res. Public Health 2021, 18, 5707. [CrossRef] [PubMed]

4. Hou, X.; Liu, J.-M.; Tang, Z.-Y.; Ruan, B.; Cao, X.-Y. The Gender Difference in Association between Home-Based Environment and Different Physical Behaviors of Chinese Adolescents. Int. J. Environ. Res. Public Health 2020, 17, 8120. [CrossRef]

5. Larson, N.I.; Wall, M.M.; Story, M.T.; Neumark-Sztainer, D.R. Home/family, peer, school, and neighborhood correlates of obesity in adolescents. Obesity 2013, 21, 1858-1869. [CrossRef] [PubMed]

6. Ip, P.; Ho, F.K.-W.; Louie, L.H.-T.; Chung, T.W.-H.; Cheung, Y.-F.; Lee, S.-L.; Hui, S.S.-C.; Ho, W.K.-Y.; Ho, D.S.-Y.; Wong, W.H.-S.; et al. Childhood Obesity and Physical Activity-Friendly School Environments. J. Pediatr. 2017, 191, 110-116. [CrossRef] [PubMed]

7. Burns, R.D.; Fu, Y.; Podlog, L.W. School-based physical activity interventions and physical activity enjoyment: A meta-analysis. Prev. Med. 2017, 103, 84-90. [CrossRef] [PubMed]

8. Sheldrick, M.P.; Maitland, C.; Mackintosh, K.A.; Rosenberg, M.; Griffiths, L.J.; Fry, R.; Stratton, G. Fry Associations between the Home Physical Environment and Children's Home-Based Physical Activity and Sitting. Int. J. Environ. Res. Public Health 2019, 16, 4178. [CrossRef]

9. Birchwood, D.; Roberts, K.; Pollock, G. Explaining differences in sport participation rates among young adults: Evidence from the South Caucasus. Eur. Phys. Educ. Rev. 2008, 14, 283-298. [CrossRef]

10. Graham, D.J.; Wall, M.M.; Larson, N.; Neumark-Sztainer, D. Multicontextual Correlates of Adolescent Leisure-Time Physical Activity. Am. J. Prev. Med. 2014, 46, 605-616. [CrossRef] [PubMed]

11. Jago, R.; Davison, K.K.; Thompson, J.L.; Page, A.S.; Brockman, R.; Fox, K.R. Parental Sedentary Restriction, Maternal Parenting Style, and Television Viewing Among 10- to 11-Year-Olds. Pediatrics 2011, 128, e572-e578. [CrossRef] [PubMed]

12. Baranowski, T.; Lin, L.S.; Wetter, D.W.; Resnicow, K.; Hearn, M.D. Theory as mediating variables: Why aren't community interventions working as desired? Ann. Epidemiol. 1997, 7, S89-S95. [CrossRef]

13. Barlow, S.E. Expert Committee Recommendations Regarding the Prevention, Assessment, and Treatment of Child and Adolescent Overweight and Obesity: Summary Report. Pediatrics 2007, 120 (Suppl. S4), S164-S192. [CrossRef]

14. Baranowski, T.; Anderson, C.; Carmack, C. Mediating variable framework in physical activity interventions: How are we doing? how might we do better? Am. J. Prev. Med. 1998, 15, 266-297. [CrossRef]

15. Anderson, J.C.; Funk, J.B.; Elliott, R.; Smith, P.H. Parental support and pressure and children's extracurricular activities: Relationships with amount of involvement and affective experience of participation. J. Appl. Dev. Psychol. 2003, 24, 241-257. [CrossRef]

16. Brockman, R.; Jago, R.; Fox, K.R.; Thompson, J.L.; Cartwright, K.; Page, A.S. "Get off the sofa and go and play": Family and socioeconomic influences on the physical activity of 10-11 year old children. BMC Public Health 2009, 9, 253. [CrossRef]

17. Tandon, P.S.; Zhou, C.; Sallis, J.F.; Cain, K.L.; Frank, L.D.; Saelens, B.E. Home environment relationships with children's physical activity, sedentary time, and screen time by socioeconomic status. Int. J. Behav. Nutr. Phys. Act. 2012, 9, 88. [CrossRef] [PubMed]

18. Määttä, S.; Ray, C.; Roos, E. Associations of parental influence and 10-11-year-old children's physical activity: Are they mediated by children's perceived competence and attraction to physical activity? Scand. J. Public Health 2013, 42, 45-51. [CrossRef] [PubMed]

19. Zahra, J.; Sebire, S.J.; Jago, R. "He's probably more Mr. sport than me"-A qualitative exploration of mothers' perceptions of fathers' role in their children's physical activity. BMC Pediatr. 2015, 15, 101. [CrossRef] [PubMed]

20. Jago, R.; Davison, K.K.; Brockman, R.; Page, A.S.; Thompson, J.; Fox, K.R. Parenting styles, parenting practices, and physical activity in 10- to 11-year olds. Prev. Med. 2011, 52, 44-47. [CrossRef] [PubMed]

21. Keech, J.J.; Hatzis, D.; Kavanagh, D.J.; White, K.M.; Hamilton, K. Parents' role constructions for facilitating physical activityrelated behaviours in their young children. Aust. J. Psychol. 2018, 70, 246-257. [CrossRef]

22. Paula, O.M. “No todo es Balón” Implicando positivamente a los padres en la práctica del fútbol en etapa formativa. Rev. Psicol. Apl. Deporte Ejerc. Físico 2017, 2, e9. [CrossRef]

23. Rhemtulla, M.; Brosseau-Liard, P.; Savalei, V. When can categorical variables be treated as continuous? A comparison of robust continuous and categorical SEM estimation methods under suboptimal conditions. Psychol. Methods 2012, 17, 354-373. [CrossRef]

24. Xia, Y.; Yang, Y. RMSEA, CFI, and TLI in structural equation modeling with ordered categorical data: The story they tell depends on the estimation methods. Behav. Res. Methods 2018, 51, 409-428. [CrossRef] [PubMed]

25. Hu, L.-T.; Bentler, P.M. Fit indices in covariance structure modeling: Sensitivity to underparameterized model misspecification. Psychol. Methods 1998, 3, 424-453. [CrossRef]

26. Marsh, H.W.; Balla, J.R.; McDonald, R.P. Goodness-of-fit indexes in confirmatory factor analysis: The effect of sample size. Psychol. Bull. 1988, 103, 391-410. [CrossRef]

27. Schermelleh-Engel, K.; Moosbrugger, H.; Müller, H. Evaluating the Fit of Structural Equation Models: Tests of Significance and Descriptive Goodness-Of-Fit Measures. Methods Psychol. Res. 2003, 8, 23-74. 
28. Bentler, P.M.; Bonett, D.G. Significance Tests and Goodness of Fit in the Analysis of Covariance Structures. Psychol. Bull. 1980, 88, 588-606. [CrossRef]

29. Bentler, P.M. Multivariate Analysis with Latent Variables: Causal Modeling. Annu. Rev. Psychol. 1980, 31, 419-456. [CrossRef]

30. Marsh, H.; Hau, K.-T.; Artelt, C.; Baumert, J.; Peschar, J.L. OECD's Brief Self-Report Measure of Educational Psychology's Most Useful Affective Constructs: Cross-Cultural, Psychometric Comparisons Across 25 Countries. Int. J. Test. 2006, 6, 311-360. [CrossRef]

31. Browne, M.W.; Cudeck, R. Alternative Ways of Assesing Model Fit. In Testing Structural Equation Models; Sage Publications: Newbury Park, CA, USA; Bevelry Hills, CA, USA, 1993; pp. 136-162.

32. Byrne, B.M.; Campbell, T.L. Cross-Cultural Comparisons and the Presumption of Equivalent Measurement and Theoretical Structure. J. Cross-Cult. Psychol. 1999, 30, 555-574. [CrossRef]

33. Hu, L.T.; Bentler, P.M. Cutoff criteria for fit indexes in covariance structure analysis: Conventional criteria versus new alternatives. Struct. Equ. Model. Multidiscip. J. 2009, 6, 1-55. [CrossRef]

34. Ministry of Education, Science, Research and Sport of the Slovak Republic. State Eductional Program; Ministry of Education, Science, Research and Sport of the Slovak Republic: Bratislava, Slovak, 2015.

35. Bolman, C.; Lechner, L.; Van Dijke, M. Question order in the assessment of misperception of physical activity. Int. J. Behav. Nutr. Phys. Act. 2007, 4, 42. [CrossRef]

36. Lau, J.; Engelen, L.; Bundy, A. Parents' Perceptions of Children's Physical Activity Compared on Two Electronic Diaries. Pediatr Exerc. Sci. 2013, 25, 124-137. [CrossRef] [PubMed]

37. Coelho, C.G.; Xavier, F.V.F.; Marques, A.C.G. School Physical Education in Times of the Covid-19 Pandemic: The Partici-pation of High School Students in Remote Education. Intercont. J. Phys. Educ. 2020, 2, e2020018.

38. Hossain, M.M.; Sultana, A.; Purohit, N. Mental health outcomes of quarantine and isolation for infection prevention: A systematic umbrella review of the global evidence. Epidemiol. Health 2020, 42, e2020038. [CrossRef]

39. Neto, L.D.O.; Elsangedy, H.M.; Tavares, V.D.D.O.; Teixeira, C.V.L.S.; Behm, D.G.; Da Silva-Grigoletto, M.E. TrainingInHomeHome-based training during COVID-19 (SARS-COV2) pandemic: Physical exercise and behavior-based approach. Revista Brasileira de Fisiologia do Exercí cio 2020, 19, 9-19. [CrossRef]

40. Link, B.G.; Phelan, J. Social Conditions as Fundamental Causes of Disease. J. Health Soc. Behav. 1995, 35, 80. [CrossRef]

41. Ferreira, I.; van der Horst, K.; Wendel-Vos, W.; Kremers, S.; Van Lenthe, F.J.; Brug, J. Environmental correlates of physical activity in youth? A review and update. Obes. Rev. 2007, 8, 129-154. [CrossRef] [PubMed]

42. Prevalence of Regular Physical Activity among Adults-United States, 2001 and 2005. JAMA 2008, 299. [CrossRef]

43. Eccles, J.S.; Freedman-Doan, C.; Frome, P.; Jacobs, J.; Yoon, K.S. Gender-Role Socialization In The Family: A Longitudinal Approach. In The Developmental Social Psychology of Gender; Lawrence Erlbaum Associates Publishers: New York, NY, USA, 2000; pp. 333-360.

44. Frome, P.M.; Eccles, J.S. Parents' influence on children's achievement-related perceptions. J. Pers. Soc. Psychol. 1998, 74, 435-452. [CrossRef]

45. Jago, R.; Anderson, C.B.; Baranowski, T.; Watson, K. Adolescent Patterns of Physical Activity: Differences by Gender, Day, and Time of Day. Am. J. Prev. Med. 2005, 28, 447-452. [CrossRef] [PubMed]

46. Tlučáková, L.; Kačúr, P. Physical Activity and Physical Fitness of Adolescents in The Prešov Region; Faculty of Sports, University of Prešov: Prešov, Slovakia, 2019; 140p.

47. Currie, C.; Zanotti, C.; Morgan, A.; Currie, D.; de Looze, M.; Roberts, C.; Samdal, O.; Smith, O.R.F.; Barnekow, V. Social Determinants of Health and Well-Being Among Young People: Health Behaviour in School-Aged Children (Hbsc) Study: International Re-port from the 2009/2010 Survey, Health Policy for Children and Adolescents; No. 6.; WHO Regional Office for Europe: Copenhagen, Denmark, 2012; 271p.

48. Wang, W.-Y.; Hsieh, Y.-L.; Hsueh, M.-C.; Liu, Y.; Liao, Y. Accelerometer-Measured Physical Activity and Sedentary Behavior Patterns in Taiwanese Adolescents. Int. J. Environ. Res. Public Health 2019, 16, 4392. [CrossRef]

49. Anderson, C.B.; Hughes, S.O.; Fuemmeler, B.F. Parent-child attitude congruence on type and intensity of physical activity: Testing multiple mediators of sedentary behavior in older children. Health Psychol. 2009, 28, 428-438. [CrossRef]

50. Carbert, N.S.; Brussoni, M.; Geller, J.; Mâsse, L.C. Familial Environment and Overweight/Obese Adolescents' Physical Activity. Int. J. Environ. Res. Public Health 2019, 16, 2558. [CrossRef]

51. Dorsch, T.E.; Smith, A.L.; Dotterer, A.M. Individual, relationship, and context factors associated with parent support and pressure in organized youth sport. Psychol. Sport Exerc. 2016, 23, 132-141. [CrossRef]

52. Pyper, E.; Harrington, D.; Manson, H. The impact of different types of parental support behaviours on child physical activity, healthy eating, and screen time: A cross-sectional study. BMC Public Health 2016, 16, 568. [CrossRef] [PubMed] 